\title{
Variables Affecting the Accuracy of Implant Master Casts: An In Vitro Pilot Study
}

\author{
Matthias Karl ${ }^{1}$ and Victor Palarie ${ }^{2}$ \\ ${ }^{1}$ Department of Prosthodontics, University of Erlangen-Nuremberg, Glueckstraße 11, 91054 Erlangen, Germany \\ ${ }^{2}$ Department of Oral and Maxillofacial Surgery, Orthopedic Stomatology and Oral Implantology, \\ University of Medicine and Pharmacy "N. Testemitanu," 158 V. Lupu Street, Orhei, 3500 Chisinau, Moldova
}

Correspondence should be addressed to Matthias Karl; matthias.karl@uk-erlangen.de

Received 3 April 2014; Accepted 25 April 2014; Published 14 May 2014

Academic Editor: Constantin Landes

Copyright (C) 2014 M. Karl and V. Palarie. This is an open access article distributed under the Creative Commons Attribution License, which permits unrestricted use, distribution, and reproduction in any medium, provided the original work is properly cited.

\begin{abstract}
Impression and master cast accuracy have been identified as being the major determinants of superstructure fit in implantsupported restorations. The goal of this in vitro investigation was to determine the effects of different transfer components, impression materials, disinfection, storage time, and stone type on master cast accuracy. Following impression making from a reference model with two internal-hex bone-level implants and master cast fabrication (eight experimental groups; $n=5$ ), a bar-type measurement device equipped with a strain gauge was fixed on all master casts while strain development was recorded. Statistical analysis was performed applying ANOVA and paired $t$-tests with the level of significance set at $\alpha=0.05$. The transfer components with plastic sleeves caused maximum misfit strain which was significantly greater as compared to click $(P=0.02)$ and open tray transfer components $(P=0.00)$. No significant effect on master cast accuracy was recorded for the parameters impression material, impression disinfection, and storage of impressions or casts. Lower strain development was observed in casts poured in type 3 stone as compared to casts poured in type 4 stone $(P=0.01)$. For the bone-level implant system considered here, the great levels of accuracy could be achieved using pick-up impressions with either click or open tray impression components.
\end{abstract}

\section{Introduction}

Due to the ankylotic fixation of dental implants in alveolar bone which is considerably more rigid than the periodontal ligament in natural teeth, restorations splinting several implants require a passive fit $[1,2]$. If this cannot be achieved, static implant loading will occur thereby increasing the risk for technical complications such as loosening of restorative screws and biologic complications such as bone loss [3].

In this context, it has been clarified that every step in the restorative process contributes to the amount of misfit present in a specific restoration [4]. Although the term "passive fit" has never been defined, most authors agree that the amount of misfit stress evoked by a certain restoration can only be minimized, for example, by using CAD/CAM technology [5], but no procedure described so far is capable of producing a totally passive fit [6]. While it has been claimed based on an in vivo pilot study that static implant loads may induce bone adaptation thereby reducing the restorations' amount of misfit, reliable insight in bone response to static loading is missing so far [7]. The restorative team should therefore still strive to optimize fit at the implant-restoration interface.

Given the high levels of accuracy reported for implant components as well as the potential of modern manufacturing techniques, impression making and master cast fabrication appear to be the most critical steps involved in superstructure fabrication. In a previous investigation on this subject, it was found that about $50 \%$ of the misfit strains evoked by an implant-supported restoration are due to inaccuracies resulting from these early steps in the fabrication process [3].

In a recent literature review on multiunit implant impression accuracy, existing knowledge has been summed up as follows [2]. Polyvinylsiloxane and polyether impression materials [8] and pick-up transfer components [9] seem to positively affect impression accuracy while splinting 
TABLE 1: Materials and parameters applied for impression making and master cast fabrication.

\begin{tabular}{|c|c|c|c|c|c|}
\hline Transfer coping & Impression material & Disinfection & Impression storage & Plaster & Cast storage \\
\hline Click transfer & Polyether & No disinfection & $1 \mathrm{~h}$ & Type IV stone & $1 \mathrm{~h}$ \\
\hline $\begin{array}{l}\text { Transfer with plastic sleeve } \\
\text { Open tray transfer }\end{array}$ & Polyvinylsiloxane & $\begin{array}{l}\text { Immersion in disinfection } \\
\text { solution for } 5 \mathrm{~min} \text { in }\end{array}$ & $24 \mathrm{~h}$ & Type III stone & $24 \mathrm{~h}$ \\
\hline
\end{tabular}

(i) Polyether (Impregum, 3M Espe, Seefeld, Germany).

(ii) Polyvinylsiloxane (Affinis, Coltene/Whaledent AG, Altstätten, Switzerland).

(iii) EuroSept Max Impression Liquid (Henry Schein Inc., Melville NY, USA).

(iv) Type IV stone (FujiRock, GC Germany GmbH, Bad Homburg, Germany; $20 \mathrm{~mL}$ water : $100 \mathrm{~g}$ powder; $45 \mathrm{~s}$ mixing time in vacuum plaster mixer).

(v) Type III stone (Hera Moldano blau, Heraeus Kulzer GmbH, Hanau, Germany; $30 \mathrm{~mL}$ water : $100 \mathrm{~g}$ powder; $30 \mathrm{~s}$ mixing time in vacuum plaster mixer).

of the transfer components may not bear an advantage [8]. Severe implant angulation negatively affects multiunit implant impression accuracy [2]. Similarly, Gonçalves and coworkers published a review article on the dimensional stability of elastomeric impression materials [10] stating that temperature and humidity as well as time until pouring may affect impression accuracy.

While several authors have addressed single aspects of impression and master cast accuracy using a variety of implant designs, a comprehensive evaluation of all parameters affecting master cast accuracy is missing. Therefore, it was the goal of this in vitro investigation to study the effects of different implant transfer components, impression materials, disinfection, impression, and cast storage as well as stone type on master cast accuracy using one implant system as a reference.

\section{Materials and Methods}

Using polyurethane resin (Biresin, Sika Deutschland GmbH, Bad Urach, Germany), two bone level implants with an internal hexagon connection (AlfaGate SCIP $3.75 \times 11.5 \mathrm{~mm}$; LOT: S031307-03) were positioned at an inter implant distance of $14.7 \mathrm{~mm}$ from center to center in an aluminum block to form a reference model [11]. The implants were positioned according to an existing patient situation with two implants placed in the region of the lower left first premolar and first molar with the premolar implant being perpendicular while the molar implant was slightly tilted mesially (Figure 1(a)).

Abutments for cement-retained restorations (Cementing post with shoulder, AGM-602-2, AlfaGate) were fixed on the implants and a bar structure with a centrally positioned flat surface connecting the abutments was waxed and cast in dental training alloy (Phantom-metal; Ag 56\%, Cu 22\%, Zn 17\%, Sn 5\%; DeguDent, Hanau, Germany). The finished bar structure was adhesively joined (Nimetic Cem, $3 \mathrm{M}$ ESPE, Seefeld, Germany) with the abutments on the reference model following silica coating and silanating (Rocatec, $3 \mathrm{M}$ ESPE, Seefeld, Germany) of relevant surfaces. A strain gauge (LY11-0.6/120; $120 \Omega$ reference resistance; Hottinger Baldwin Messtechnik GmbH, Darmstadt, Germany) was positioned on the occlusal surface of the bar structure with the sensing element oriented in the mesial-distal direction (Figure 1(b)). A measurement amplifier (Spider 8; Hottinger Baldwin Messtechnik GmbH, Darmstadt, Germany) and analyzing

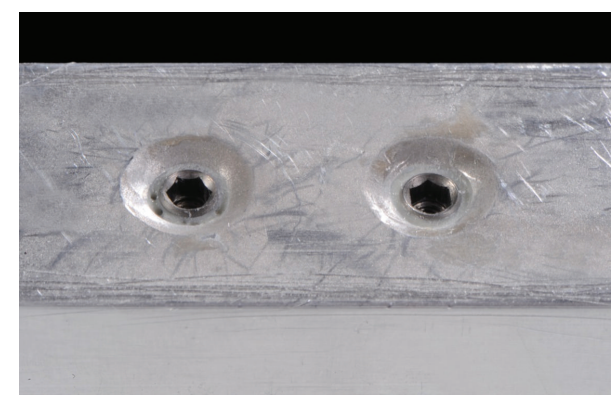

(a)

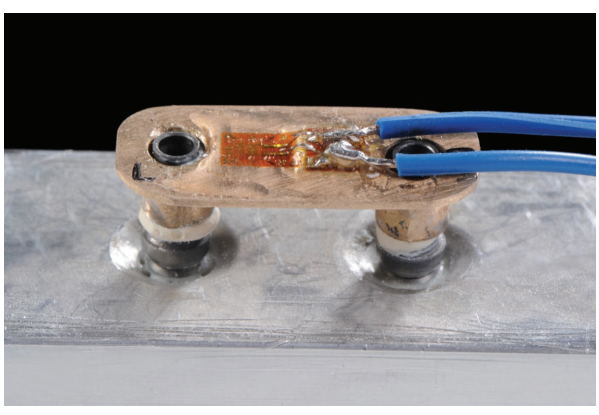

(b)

Figure 1: (a) Two internal-hex bone-level dental implants with a distance of $14.7 \mathrm{~mm}$ from center to center were embedded in an aluminum block to serve as reference model for the study. (b) Abutments for cement-retained restorations were passively connected on the reference model using an individually cast metal plate which was adhesively joined with the abutments. A strain gauge was fixed on the occlusal surface of the plate which allowed capturing unidirectional deformations during fixation of this measuring device.

software (BEAM for Spider, AMS Gmbh, Chemnitz, Germany) were used for capturing strains occurring in this measuring device due to its fixation on the implants.

A total of 40 impressions $(n=5)$ [12] were made from the patient model, using all types of the implant manufacturer's transfer components (Figure 2) in combination with custommade impression trays (Palatray XL; Heraeus Kulzer, Hanau, Germany). Implant analogs were attached to the transfer copings and standardized master casts (Figure 3) were fabricated using a silicone mold (Sil 18 Doubliersilikon, Dr. Ihde Dental AG, Gommiswald, Switzerland). The parameters varied during impression making and master cast fabrication are detailed in Table 1. 


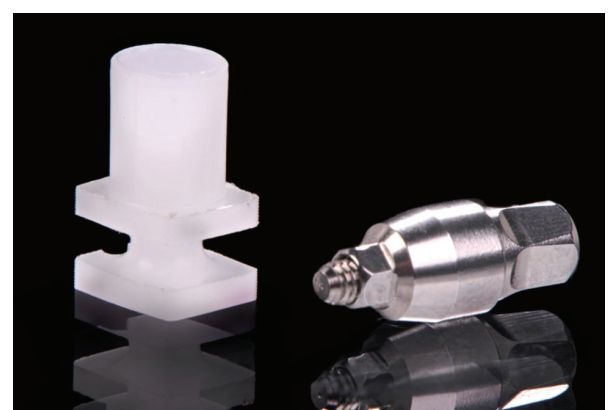

(a)

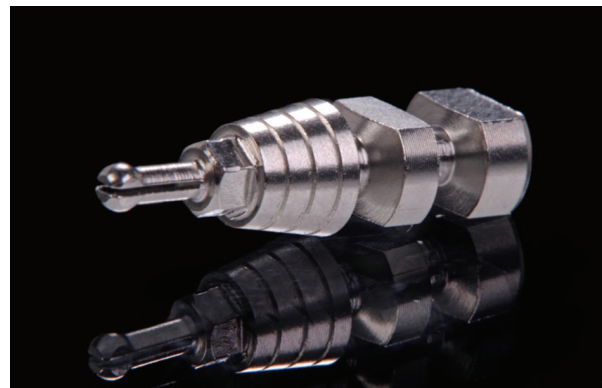

(b)

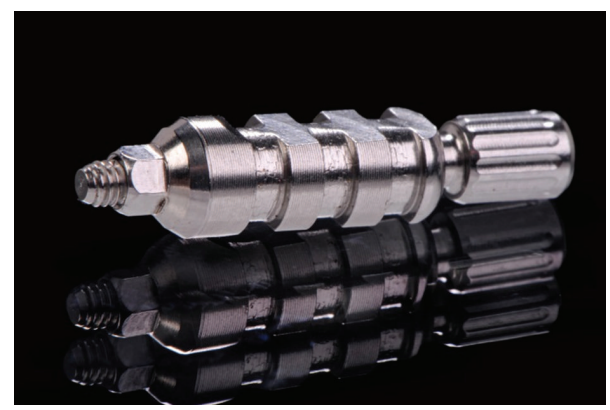

(c)

FIGURE 2: Transfer copings used for the study: (a) transfer with plastic sleeve; (b) click transfer; (c) open tray transfer.

For evaluating the accuracy of the master casts, the strain gauge on the measuring device was set to zero followed by positioning of the device on a specific master cast and tightening of the abutment screws to $25 \mathrm{~N} \mathrm{~cm}$ using the implant manufacturer's manual ratchet $[9,13]$. The final strain values after 2 min were recorded for analysis (Figure 4 ).

Statistical analysis for evaluating the effect of the parameters varied (Table 1) was based on the absolute strain readings. Following analysis of variance (ANOVA), pairwise $t$-tests were conducted with the level of significance set at $\alpha=0.05$.

\section{Results}

Mean strain development on the master casts ranged from $116.6 \mu \mathrm{m} / \mathrm{m}$ to $693.65 \mu \mathrm{m} / \mathrm{m}$ (Table 2) with ANOVA indicating significant differences between the groups tested $(P=$ 0.01 ). The results from pairwise comparisons between the experimental groups are given in Table 3 .

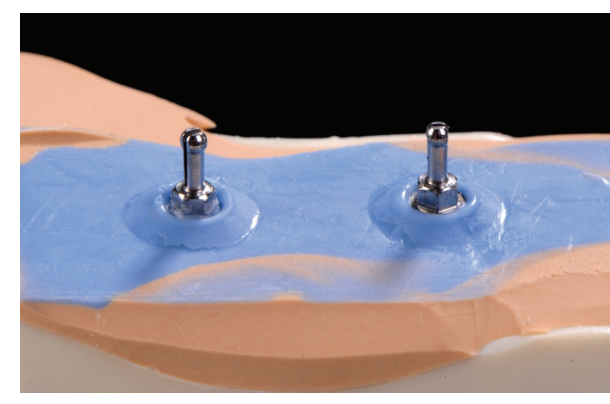

(a)

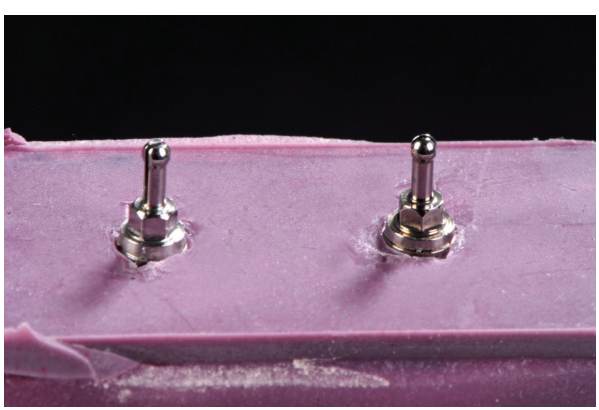

(b)

Figure 3: Examples of impressions made with the use of click transfer components and (a) polyvinylsiloxane (b) polyether.

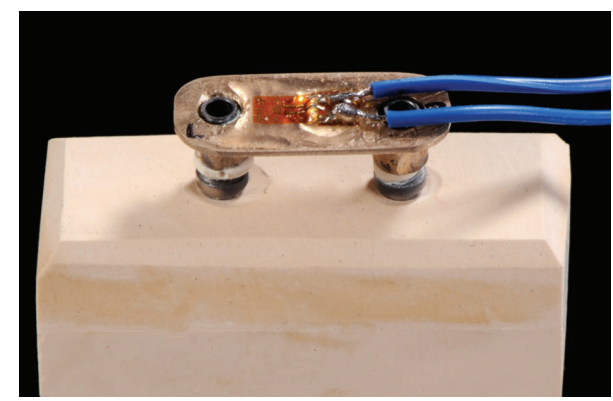

(a)

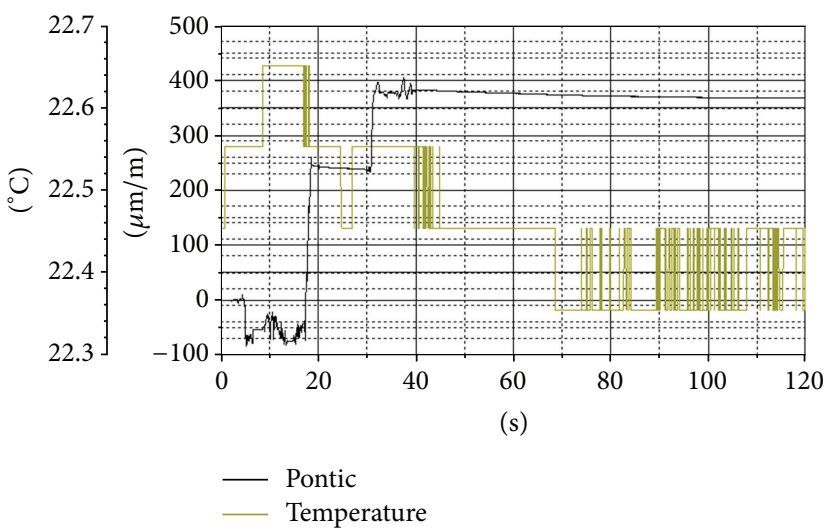

(b)

Figure 4: (a) Measuring device mounted on the master cast. (b) Screen shot of the analyzing software displaying strain development on the measuring device as resulting from fixation on the master cast. 
TABLE 2: Mean strain values and standard deviations measured for all combinations of parameters tested.

\begin{tabular}{lcccccccc}
\hline Group & $\begin{array}{c}\text { Transfer } \\
\text { coping }\end{array}$ & Impression material & Disinfection & Impression storage & Stone type & Cast storage $\begin{array}{c}\text { Mean strain } \\
\text { value }[\mu \mathrm{m} / \mathrm{m}]\end{array}$ & $\begin{array}{c}\text { Standard } \\
\text { deviation }\end{array}$ \\
\hline 1 & Click & Polyether & No & $1 \mathrm{~h}$ & FujiRock & $1 \mathrm{~h}$ & 252.84 & 119.87 \\
2 & Plastic sleeve & Polyether & No & $1 \mathrm{~h}$ & FujiRock & $1 \mathrm{~h}$ & 506.82 & 114.78 \\
3 & Open tray & Polyether & No & $1 \mathrm{~h}$ & FujiRock & $1 \mathrm{~h}$ & 116.16 & 51.26 \\
4 & Click & Polyvinyl-Siloxane & No & $1 \mathrm{~h}$ & FujiRock & $1 \mathrm{~h}$ & 174.58 & 151.08 \\
5 & Open tray & Polyether & Yes & $1 \mathrm{~h}$ & FujiRock & $1 \mathrm{~h}$ & 195.78 & 57.71 \\
6 & Click & Polyether & No & $24 \mathrm{~h}$ & FujiRock & $1 \mathrm{~h}$ & 693.65 & 566.17 \\
7 & Plastic sleeve & Polyether & No & $1 \mathrm{~h}$ & Moldano Blue & $1 \mathrm{~h}$ & 149.34 & 13.22 \\
8 & Open tray & Polyether & No & $1 \mathrm{~h}$ & FujiRock & $24 \mathrm{~h}$ & 253.86 & 135.11 \\
\hline
\end{tabular}

TABle 3: $P$-values resulting from pairwise comparisons between groups based on $t$-tests; significant differences $(P<0.05)$ are written in bold.

\begin{tabular}{|c|c|c|c|c|c|c|c|c|}
\hline Group & 1 & 2 & 3 & 4 & 5 & 6 & 7 & 8 \\
\hline 1 & & 0.02 & 0.10 & 0.41 & 0.44 & 0.16 & 0.18 & 0.99 \\
\hline 2 & & & 0.00 & 0.01 & 0.01 & 0.51 & 0.01 & 0.03 \\
\hline 3 & & & & 0.45 & 0.09 & 0.08 & 0.29 & 0.13 \\
\hline 4 & & & & & 0.78 & 0.11 & 0.73 & 0.43 \\
\hline 5 & & & & & & 0.12 & 0.21 & 0.47 \\
\hline 6 & & & & & & & 0.10 & 0.16 \\
\hline 7 & & & & & & & & 0.22 \\
\hline 8 & & & & & & & & \\
\hline
\end{tabular}

Comparing the different impression copings used, the transfer components with plastic sleeves caused maximum misfit strain which was significantly greater as compared to click $(P=0.02)$ and open tray transfer components $(P=$ $0.00)$. No significant difference in master cast accuracy could be found between open tray and click transfer $(P=0.10)$.

The use of polyvinylsiloxane impression material had no significant effect on misfit strain as compared to the use of polyether impression material $(P=0.41)$. Similarly, disinfecting polyether impressions made with open tray transfer copings had no significant effect on resulting master cast accuracy $(P=0.09)$. Due to a dramatically increased variability in strain development measured in master casts which had been poured after $24 \mathrm{~h}$ of impression storage, no significant difference compared to casts produced after $1 \mathrm{~h}$ storage time could be detected $(P=0.16)$. Similarly, cast storage for $24 \mathrm{~h}$ also led to an increase in variability which resulted in a nonsignificant difference as compared to casts stored for one hour $(P=0.13)$. On the contrary, significantly lower strain development was observed in casts poured in type 3 stone as compared to casts poured in type 4 stone $(P=0.01)$.

\section{Discussion}

Considerable strain development was found in each master cast tested indicating that none of the impression procedures employed allowed transferring the original implant positions without positional errors $[3,5]$.
While no difference in accuracy could be found between master casts made from pick-up impressions (click and open tray impression copings; groups 1 and 3), the use of repositioning impressions (transfer coping with plastic sleeve; group 2) led to significantly greater distortions. A possible explanation for that may be the fact that the plastic sleeve is completely covered by impression material not allowing for visual control when the implant analog is reattached. This may be specific for bone level implants as in previous investigations; no difference between pick-up and repositioning impressions could be found when a soft-tissue level implant was used [3].

In the study at hand, the choice of impression material used had no effect on the resulting master cast accuracy which is consistent with a comparable in vitro study using tissue level implants [13]. However, the literature is inconclusive in this matter as both reports favoring polyvinylsiloxane [8] or polyether [14] can be found.

It has been argued that disinfection of impressions may alter material properties such as wettability [15] and cause dimensional changes $[16,17]$ which may in turn affect master cast accuracy. The disinfecting procedure employed here comprised immersion of the impression in disinfection solution for $5 \mathrm{~min}$ followed by rinsing under tap water. Similar to two in vitro studies conducted by Melilli and coworkers as well as by Yilmaz and coworkers, no negative effect of this procedure on master cast accuracy could be detected $[18,19]$.

Delayed pouring of impressions has also been shown to negatively affect dimensional stability [17] particularly in polyether based materials which may absorb water due to their hydrophilic material properties [20]. In the study at hand, no significant effect of impression storage for $24 \mathrm{~h}$ was noticed although delayed pouring caused an increased variation in master cast accuracy. This limited effect of impression storage seems to be consistent with a study conducted by Franco and coworkers where only minor changes were found when pouring of the impressions was performed within $24 \mathrm{~h}$ [21]. Similar findings were reported for polyvinylsiloxane duplicating materials even after several weeks of storage [22].

Whereas delayed pouring of the impression cannot be often avoided especially when working with commercial dental laboratories, the timepoint of when to start working on a master cast can be determined by the technician. In this context, it has been shown that expansion of the model 
material continues for several hours after the start of the mixing phase [23] followed by a contractive phase which may last several days [24]. In the current study, no significant effect of cast storage could be detected although a trend towards greater mean strain values was observed after $24 \mathrm{~h}$ of storage time. Besides possible dimensional changes in the master casts, a reduction in moisture content of the stone could have increased the elastic modulus of the model material which would have also caused an increase in strain development on the measuring device. A comparable difference in elastic modulus between type 3 and type 4 stones used may have led to significantly lower strain readings in casts produced from type 3 stone which is normally expected to be less accurate.

A variety of potential measurement techniques which could have been used for the purpose of this study have been described in the literature including coordinate measurement machines [9], 3D image correlation procedures [22, 25], and $\mu \mathrm{CT}$ scanning [26]. As repeatedly described, a strain gauge equipped restoration fitting a reference model may also be used for assessing the accuracy of master casts $[9,12,14$, $27,28]$. Although it may be claimed that more sophisticated techniques provide data in all directions of space separately [11], the major advantage of the measurement method applied here seems to be that these deformations are integrated in one strain value [25]. This amount of strain could also be captured in a clinical situation where a restoration fabricated on a specific master cast was positioned and measured in the patient's oral cavity [7]. Nevertheless, the data presented only allow for relative comparisons to be made based on the particular situation tested here [2] and it has to be taken into account that numerous combinations of 3D deformations could cause an identical strain signal with the set-up chosen. For this reason, the absolute values of the strain readings were used for statistical analysis [3].

Although comparable studies have been conducted with a similar sample size [12], the limited number of samples tested and the in vitro test setting chosen as well as the fact that only one implant system was used have to be seen as systematic limitations of this investigation. In addition to the variables tested here, implant angulation $[2,28,29]$ and splinting of the transfer components $[2,8,12,28]$ would have represented additional parameters. However, based on the literature available, these variables seem to have only a minor effect as compared to the parameters evaluated in the present study.

\section{Conclusion}

Within the limitations of this in vitro study, it appears that the transfer components chosen have a prevailing effect on master cast accuracy. For the bone-level implant system considered here, the greatest levels of accuracy could be achieved using pick-up impressions with either click or open tray impression components.

\section{Conflict of Interests}

The authors declare that there is no conflict of interests regarding the publication of this paper.

\section{Acknowledgment}

The implant components required for this study were generously provided by AlfaGate, Kfar Qara, Israel.

\section{References}

[1] R. Giordano II, "Issues in handling impression materials," General dentistry, vol. 48, no. 6, pp. 646-648, 2000.

[2] M. R. Baig, "Multi-unit implant impression accuracy: a review of the literature," Quintessence International, vol. 45, pp. 39-51, 2014.

[3] S. M. Heckmann, M. Karl, M. G. Wichmann, W. Winter, F. Graef, and T. D. Taylor, "Cement fixation and screw retention: parameters of passive fit-an in vitro study of threeunit implant-supported fixed partial dentures," Clinical Oral Implants Research, vol. 15, no. 4, pp. 466-473, 2004.

[4] K. B. Tan, "The clinical significance of distortion in implant prosthodontics: is there such a thing as passive fit?" Annals of the Academy of Medicine Singapore, vol. 24, no. 1, pp. 138-157, 1995.

[5] M. Karl, F. Graef, P. Schubinski, and T. Taylor, "Effect of intraoral scanning on the passivity of fit of implant supported fixed dental prostheses," Quintessence International, vol. 43, pp. 555-562, 2012.

[6] A. G. Wee, S. A. Aquilino, and R. L. Schneider, "Strategies to achieve fit in implant prosthodontics: a review of the literature," International Journal of Prosthodontics, vol. 12, no. 2, pp. 167-178, 1999.

[7] M. Karl, F. Graef, S. Heckmann, and T. Taylor, "A methodology to study the effects of prosthesis misfit over time: an in vivo model," The International Journal of Oral \& Maxillofacial Implants, vol. 24, no. 4, pp. 689-694, 2009.

[8] M. Buzayan, M. R. Baig, and N. Yunus, "Evaluation of accuracy of complete-arch multiple-unit abutment-level dental implant impressions using different impression and splinting materials," The International Journal of Oral \& Maxillofacial Implants, vol. 28, pp. 1512-1520, 2013.

[9] T. Balamurugan and P. Manimaran, "Evaluation of accuracy of direct transfer snapon impression coping closed tray impression technique and direct transfer open tray impression technique: an in vitro study," Journal of Indian Prosthodontic Society, vol. 13, pp. 226-232, 2013.

[10] F. S. Gonçalves, D. A. Popoff, C. D. Castro, G. C. Silva, C. S. Magalhães, and A. N. Moreira, "Dimensional stability of elastomeric impression materials: a critical review of the literature," European Journal of Prosthodontics and Restorative Dentistry, vol. 19, pp. 163-166, 2011.

[11] M. Alikhasi, H. Siadat, A. Monzavi, and F. Momen-Heravi, "Three-dimensional accuracy of implant and abutment level impression techniques: effect on marginal discrepancy," Journal of Oral Implantology, vol. 37, no. 6, pp. 649-657, 2011.

[12] M. M. Naconecy, E. R. Teixeira, R. S. A. Shinkai, L. C. F. Frasca, and A. Cervieri, "Evaluation of the accuracy of 3 transfer techniques for implant-supported prostheses with multiple abutments," International Journal of Oral and Maxillofacial Implants, vol. 19, no. 2, pp. 192-198, 2004.

[13] M. C. Çehreli and K. Akça, "Impression techniques and misfitinduced strains on implant-supported superstructures: an in vitro study," International Journal of Periodontics and Restorative Dentistry, vol. 26, no. 4, pp. 379-385, 2006. 
[14] J. A. Inturregui, S. A. Aquilino, J. S. Ryther, and P. S. Lund, "Evaluation of three impression techniques for osseointegrated oral implants," The Journal of Prosthetic Dentistry, vol. 69, no. 5, pp. 503-509, 1993.

[15] S. Shetty, G. Kamat, and R. Shetty, "Wettability changes in polyether impression materials subjected to immersion disinfection," Dental Research Journal (Isfahan), vol. 10, pp. 539-544, 2013.

[16] N. Martin, M. V. Martin, and N. M. Jedynakiewicz, "The dimensional stability of dental impression materials following immersion in disinfecting solutions," Dental Materials, vol. 23, no. 6, pp. 760-768, 2007.

[17] U. Nassar, A. Oko, S. Adeeb, M. El-Rich, and C. Flores-Mir, "An in vitro study on the dimensional stability of a vinyl polyether silicone impression material over a prolonged storage period," The Journal of Prosthetic Dentistry, vol. 109, no. 3, pp. 172-178, 2013.

[18] D. Melilli, A. Rallo, A. Cassaro, and G. Pizzo, "The effect of immersion disinfection procedures on dimensional stability of two elastomeric impression materials," Journal of Oral Science, vol. 50, no. 4, pp. 441-446, 2008.

[19] H. Yilmaz, C. Aydin, B. Gul, C. Yilmaz, and M. Semiz, "Effect of disinfection on the dimensional stability of polyether impression materials," Journal of Prosthodontics, vol. 16, no. 6, pp. 473-479, 2007.

[20] T. Endo and W. J. Finger, "Dimensional accuracy of a new polyether impression material," Quintessence International, vol. 37, no. 1, pp. 47-51, 2006.

[21] E. B. Franco, L. F. da Cunha, and A. R. Benetti, "Effect of storage period on the accuracy of elastomeric impressions," Journal of Applied Oral Science, vol. 15, no. 3, pp. 195-198, 2007.

[22] R. Pant, A. S. Juszczyk, R. K. F. Clark, and D. R. Radford, "Long-term dimensional stability and reproduction of surface detail of four polyvinyl siloxane duplicating materials," Journal of Dentistry, vol. 36, no. 6, pp. 456-461, 2008.

[23] R. H. Heshmati, W. W. Nagy, C. G. Wirth, and V. B. Dhuru, "Delayed linear expansion of improved dental stone," The Journal of Prosthetic Dentistry, vol. 88, no. 1, pp. 26-31, 2002.

[24] G. Franz, "Correct timing of work on a hard plaster of Paris model," Deutsche Zahnarztliche Zeitschrift, vol. 34, no. 9, pp. 694-697, 1979.

[25] D. T. Chandran, D. C. Jagger, R. G. Jagger, and M. E. Barbour, "Two- and three-dimensional accuracy of dental impression materials: effects of storage time and moisture contamination," Bio-Medical Materials and Engineering, vol. 20, no. 5, pp. 243249, 2010.

[26] S. Steinhäuser-Andresen, A. Detterbeck, C. Funk et al., "Pilot study on accuracy and dimensional stability of impression materials using industrial CT technology," Journal of Orofacial Orthopedics, vol. 72, no. 2, pp. 111-124, 2011.

[27] A. A. Castilho, A. N. Kojima, S. M. B. Pereira et al., "In vitro evaluation of the precision of working casts for implantsupported restoration with multiple abutments," Journal of Applied Oral Science, vol. 15, no. 3, pp. 241-246, 2007.

[28] J.-H. Choi, Y.-J. Lim, S.-H. Yim, and C.-W. Kim, "Evaluation of the accuracy of implant-level impression techniques for internal-connection implant prostheses in parallel and divergent models," International Journal of Oral and Maxillofacial Implants, vol. 22, no. 5, pp. 761-768, 2007.

[29] K. Al-Abdullah, R. Zandparsa, M. Finkelman, and H. Hirayama, "An in vitro comparison of the accuracy of implant impressions with coded healing abutments and different implant angulations," The Journal of Prosthetic Dentistry, vol. 110, no. 2, pp. 90100, 2013. 


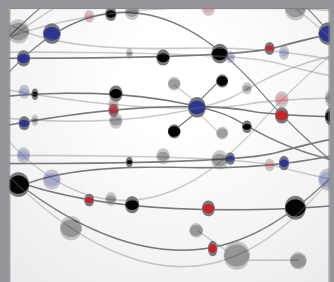

The Scientific World Journal
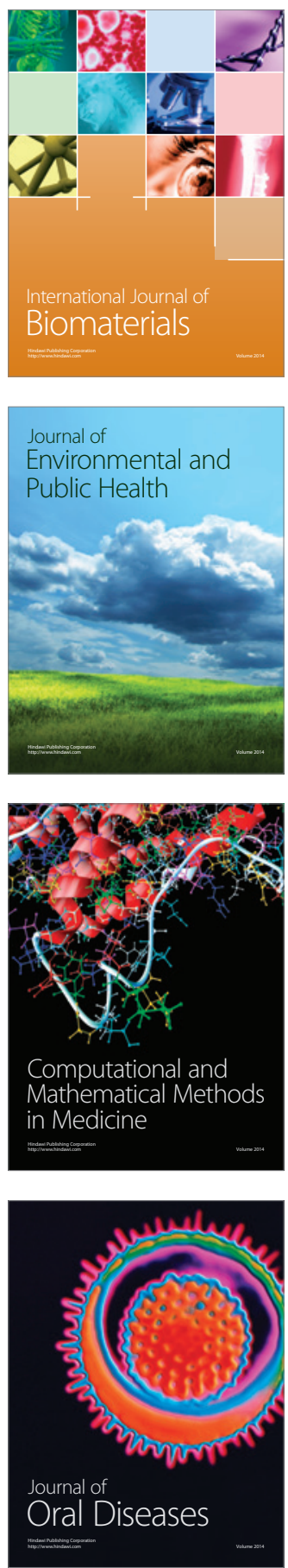
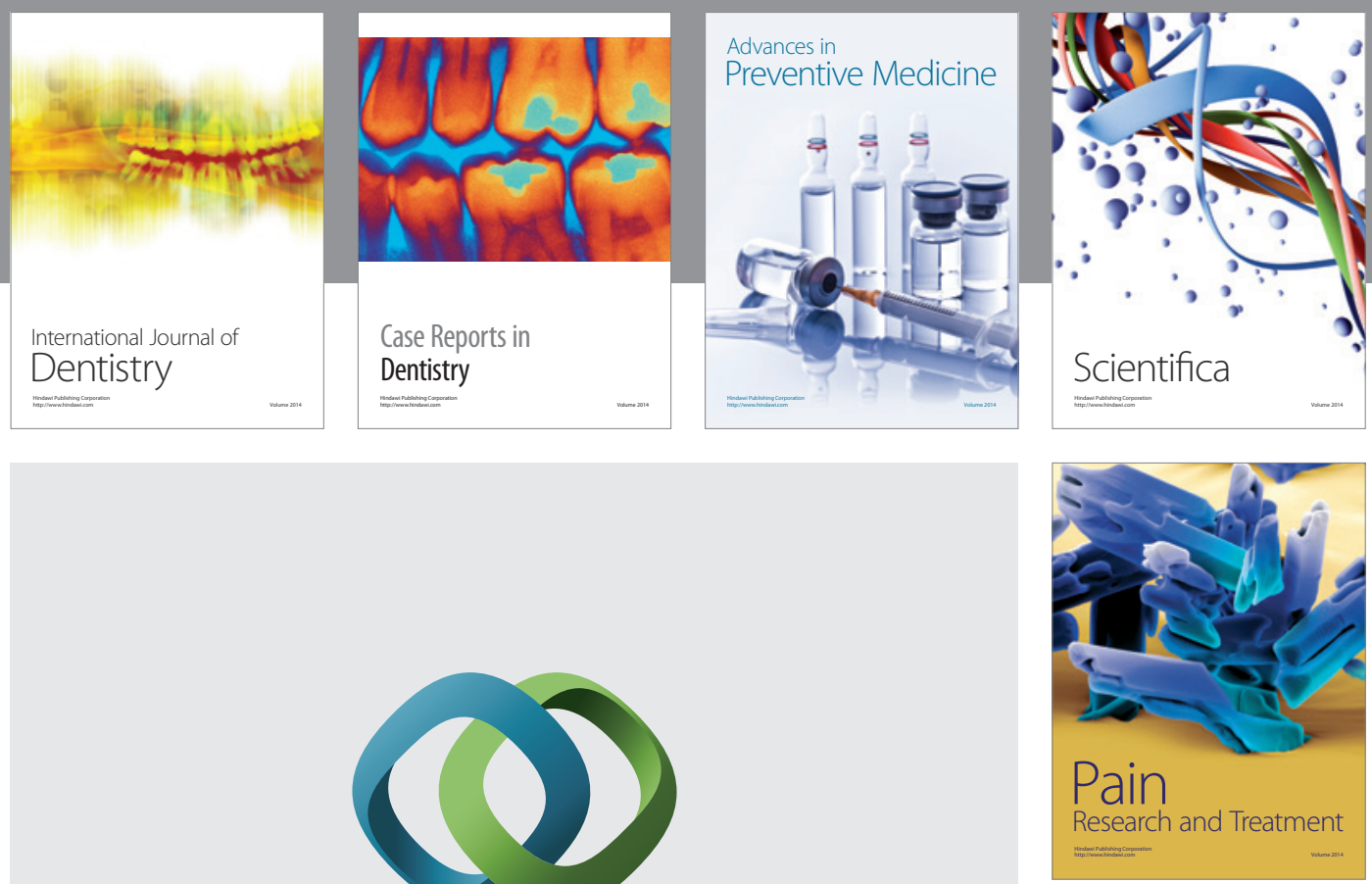

\section{Hindawi}

Submit your manuscripts at

http://www.hindawi.com
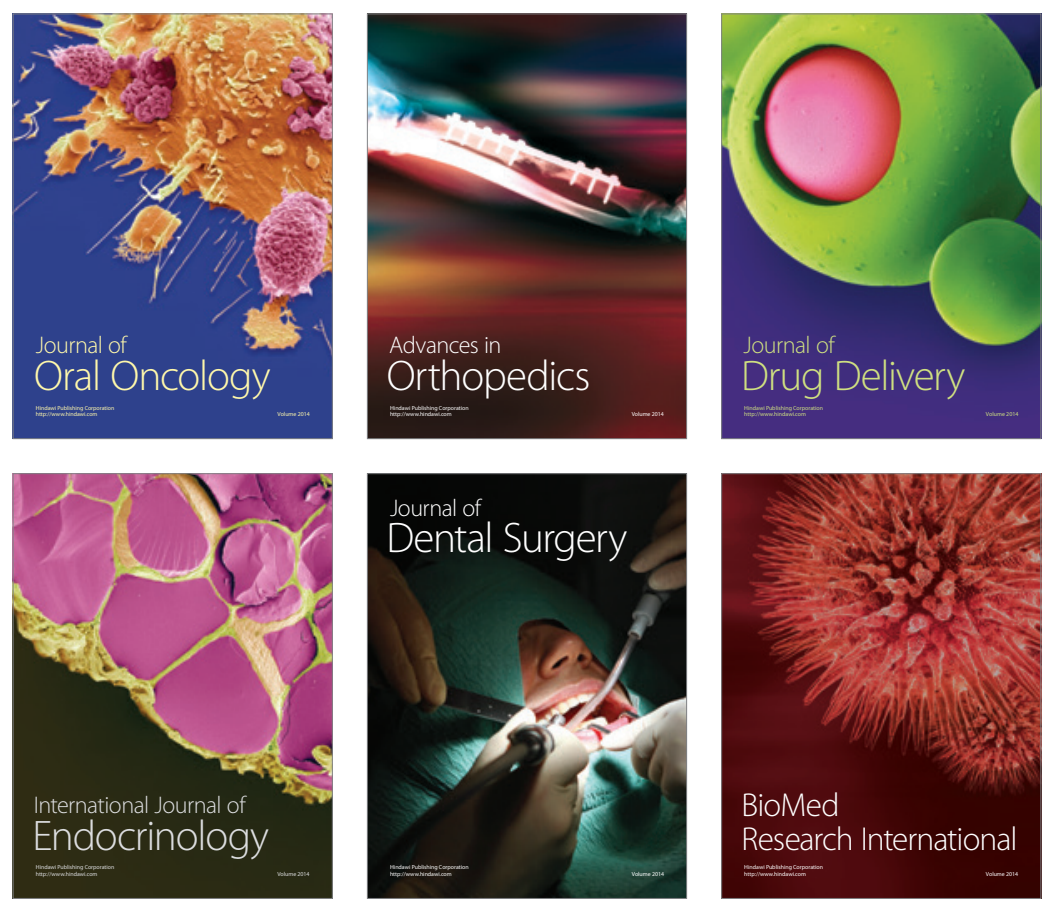

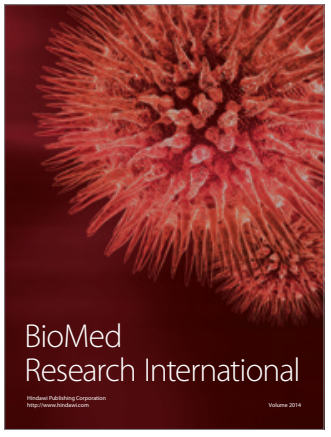

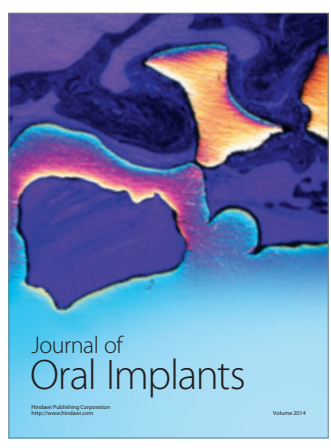
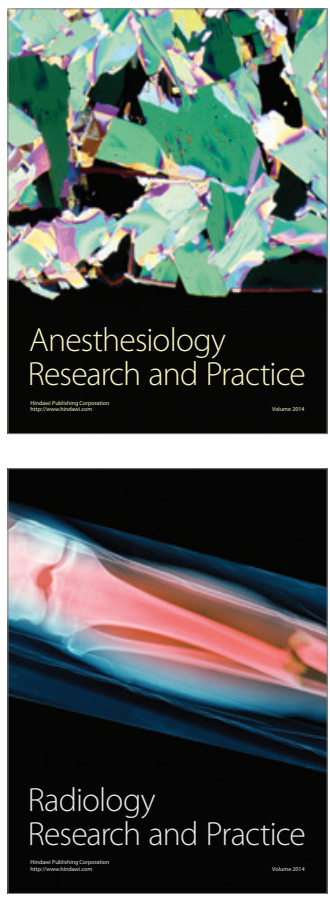